\title{
German Spaceborne SAR Missions
}

\author{
Alberto Moreira ${ }^{1}$, Manfred Zink ${ }^{1}$, Michael Bartusch ${ }^{2}$, Adriana Elizabeth Nuncio Quiroz ${ }^{2}$, Samuel Stettner ${ }^{2}$ \\ Email: \{alberto.moreira, manfred.zink, michael.bartusch, elizabeth.nuncioquiroz, samuel.stettner\}@dlr.de \\ ${ }^{1}$ Microwaves and Radar Institute, German Aerospace Center (DLR), Oberpfaffenhofen, Germany \\ ${ }^{2}$ Space Agency, German Aerospace Center (DLR), Bonn, Germany
}

\begin{abstract}
This paper provides an overview of the German spaceborne radar program starting with the $\mathrm{X}$-band synthetic aperture radar (SAR) instrument on board the Shuttle Imaging Radar missions (SIR-C/X-SAR) in 1994, followed by the Shuttle Radar Topography Mission (SRTM) in 2000. The German national satellite radar program began in 2007 with the launch of the satellite TerraSAR-X which is providing since then highresolution $X$-band images for scientific, commercial and governmental applications. TanDEM-X, an almost identical twin of TerraSAR-X, was launched in 2010. Both satellites fly in close formation to form the first bistatic, single-pass interferometric spaceborne SAR system. A global, highresolution digital elevation model (DEM) of the Earth's surface with unprecedented accuracy has been generated and made available for a broad community since 2016. A second edition of global DEM, denoted as Change DEM, will be available in 2022. Both satellites are still fully functional and have enough consumables for several additional years of operation. The paper concludes with an overview of the innovative concepts, technologies, imaging techniques and applications planned for the future national SAR missions Tandem-L and HRWS.
\end{abstract}

Keywords- Spaceborne SAR, Bistatic SAR, Interferometry, Digital Beamforming, High-Resolution Wide-Swath (HRWS)

\section{INTRODUCTION}

Since the 1980s, Germany has built up considerable expertise in spaceborne SAR missions. Early developments were in cooperation with NASA/JPL (Jet Propulsion Laboratory). The Shuttle Imaging Radar Missions SIR-C/XSAR consisted of two flights in April and September 1994 aiming to demonstrate the potential of fully polarimetric radar systems in three different frequency bands for a variety of applications. Germany developed the X-SAR radar system in cooperation with Italy, the USA developed the radar systems in $\mathrm{C}$ and $\mathrm{L}$ band. Both SIR-C/X-SAR missions opened a new era in scientific remote sensing with multi-frequency, multipolarimetric SAR systems. The combination of L, C and Xband, as well as the different polarizations of the acquired data takes over selected test sites are unique until today [1].

SRTM, the Shuttle Radar Topography Mission [2], was a highlight in Germany's radar activities in cooperation with NASA/JPL. Space Shuttle Endeavour started on February 11, 2000 , with the goal to map the topography of the Earth's surface using two radar systems. In total 3,600 Gigabyte have been recorded in the course of only eleven days. Secondary antennas mounted at the end of a $60 \mathrm{~m}$ long boom allowed a topographic mapping of $80 \%$ of the Earth's land surface with a height accuracy of ca. $10 \mathrm{~m}$. Germany participated in the mission with an interferometric X-band radar system (XSAR) that acquired approximately $40 \%$ of land surface with the increased accuracy of approximately $6 \mathrm{~m} \mathrm{[3].}$

The actual highlight of the German spaceborne radar program is the successful implementation of the TanDEM-X mission [4], [5]. It demonstrates the DLR's capabilities in the development of highly innovative mission concepts in

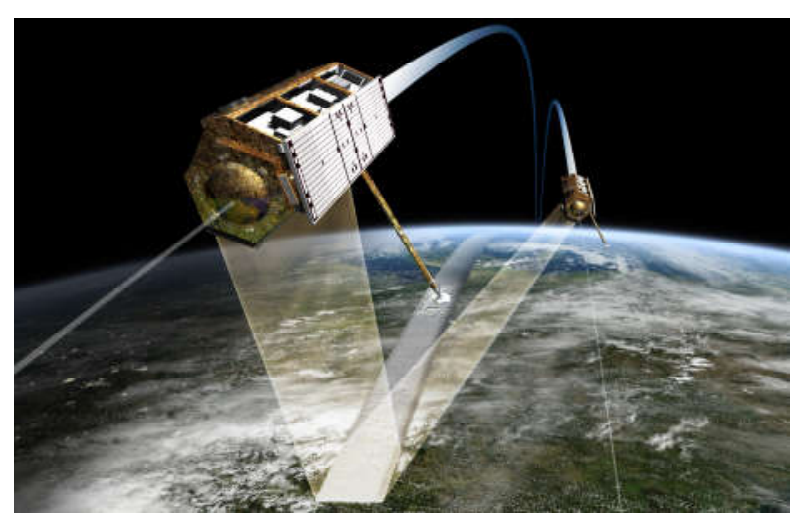

Fig. 1. Since 2010 TerraSAR-X and TanDEM-X have been flying in close formation operating as a bistatic radar interferometer. A global digital elevation model (DEM) of the Earth's surface has been generated and is available since 2016 for scientific, commercial and governmental applications.

response to demanding mission objectives, in leading the project realization facing a number of challenges, and in directing and monitoring the entire generation process from global data acquisition through to the final digital elevation model (DEM). The global TanDEM-X DEM is of outstanding quality and exceeds all its specifications, in case of the absolute height accuracy even by one order of magnitude (see section III).

TanDEM-X can be seen as a precursor for Tandem-L [6], [7], a pioneering mission for climate and environmental research. Tandem-L is built on a very strong science case developed in a joint effort by eight Helmholtz research centers and an international team of more than 100 scientists. Aiming at the observation of dynamic processes in the bio-, geo-, hydro- and cryosphere, this mission requires a novel SAR instrument concept based on digital beamforming in combination with a large reflector antenna. A swath width of up to $350 \mathrm{~km}$ enables weekly global coverage as a precondition to observe Earth's system dynamics.

Given the great success of TanDEM-X, a novel concept for an X-band SAR mission denoted as High-Resolution Wide-Swath (HRWS) mission has been proposed [17]. It consists of a main high-resolution X-band radar satellite and 3 small, receive-only satellites in formation flight. The small satellites, following the MirrorSAR concept [18], operate as radar transponders and allow an effective, low-cost implementation of a multistatic interferometric system for high-resolution DEM generation and for secondary mission objectives as, for example, along-track interferometry.

The following sections provide a brief overview of the current missions TerraSAR-X and TanDEM-X. The mission proposals Tandem-L and HRWS are presented in Sections IV and $\mathrm{V}$, respectively. Conclusions summarize the achievements and the potential way forward for future spaceborne SAR missions. 


\section{TERRASAR-X}

The first civilian German radar satellite TerraSAR-X [8] was launched from the Russian Baikonur Cosmodrome in Kazakhstan into a $514 \mathrm{~km}$, 11-day repeat cycle, sunsynchronous dusk-dawn orbit on June 15, 2007. TerraSAR-X features an advanced high-resolution X-band SAR instrument (center frequency $9.65 \mathrm{GHz}$, chirp bandwidth up to $300 \mathrm{MHz}$ ), which can be operated in spotlight, stripmap, and ScanSAR mode with full polarization capability.

The flexible design of TerraSAR-X made it possible to implement even advanced imaging modes on an operational SAR instrument after the satellite launch. It includes a very wide-swath ScanSAR mode as well as a staring spotlight mode with an azimuth resolution up to $25 \mathrm{~cm}$. In staring spotlight, the rotation center of the beam is fixed in the center of the scene, and the azimuth steering angles are increased to $\pm 2.2^{\circ}$ compared to $\pm 0.375^{\circ}$ in the standard sliding spotlight mode. Whereas grating lobes in the sliding spotlight are $20 \mathrm{~dB}$ below the desired steering direction, they become equally high at the extreme steering angles in the staring spotlight mode. The resulting azimuth ambiguities have been controlled through optimized PRF settings and scene size reductions [9], [10]. Both wide ScanSAR and staring spotlight imaging modes generated highly interesting new products. For this reason, it was decided to implement them as new imaging operational modes without interruption of the mission operation. The operational wide ScanSAR mode features a swath width of up to $260 \mathrm{~km}$ at a resolution of approximately $40 \mathrm{~m}$. Both new modes were well received by the scientific and commercial users.

In operation for more than 13 years, TerraSAR-X has achieved remarkable results. Despite a satellite age well beyond the nominal 5.5-year life-time, no significant technical flaws have been encountered.

\section{TANDEM-X}

On June 21, 2010 the still unique TanDEM-X (TerraSAR-X add-on for Digital Elevation Measurements) mission was launched and opened a new era in spaceborne radar remote sensing [4], [5]. The first formation flying radar system was built by extending the TerraSAR-X Synthetic Aperture Radar (SAR) mission by a second, TerraSAR-X-like satellite TanDEM-X (see Fig. 1). The resulting large singlepass SAR interferometer features flexible baseline selection enabling the acquisition of highly accurate cross-track interferograms not impacted by temporal decorrelation and atmospheric disturbances. The primary objective of the mission was the generation of a global Digital Elevation Model (DEM) with unprecedented accuracy (12 $\mathrm{m}$ horizontal resolution and $2 \mathrm{~m}$ relative height accuracy). While the main mission phase for DEM data acquisition has been finished in 2014, the processing of the global TanDEM-X DEM was concluded in September 2016.

\section{A. Mission Concept}

The TanDEM-X mission has been and still is the first distributed SAR system in space. Late in the development, necessary features required for the TanDEM-X mission have been implemented on TerraSAR-X (TSX). Examples are additional X-band horn antennas for inter-satellite phase synchronization, a dual-frequency GPS receiver for precise orbit and baseline determination, excellent radio frequency
(RF) phase stability of the SAR instrument, and pulse repetition frequency (PRF) synchronization based on GPS as a common time reference. The second satellite (TDX, launched on June 21, 2010) is mostly a rebuild of TSX with only minor modifications like an additional cold gas propulsion system for formation fine tuning.

Flying in close formation at typical distances of a few hundred meters the two satellites perform single-pass interferometry and acquire cross-track interferograms without temporal or atmospheric decorrelation. The so-called Helix formation combines an out-of-plane (horizontal) orbital displacement by small differences in the right ascension of the ascending nodes with a radial (vertical) separation by different eccentricity vectors resulting in a helix-like relative movement of the satellites along the orbit.

TanDEM-X can acquire interferometric data in different configurations [4], [5]: examples are the bistatic, pursuit monostatic, and alternating bistatic modes. The different interferometric configurations can be further combined with different TSX and TDX SAR imaging modes like stripmap, ScanSAR, and spotlight. Operational DEM generation is performed using the bistatic stripmap mode in single polarization $(\mathrm{HH})$. This mode uses either TSX or TDX as a transmitter to illuminate a common radar footprint on the Earth's surface. The scattered signal is then recorded by both satellites simultaneously. This simultaneous data acquisition makes dual use of the available transmit power and is mandatory to avoid possible errors from temporal decorrelation and atmospheric disturbances. Nominal DEM acquisitions were performed in right-looking observation mode in ascending/descending orbits over the Northern and Southern hemisphere, respectively. Interferometric data over all land masses have been acquired at least twice, mountainous regions even up to 6 or 8 times.

The interferometric calibration is key to achieve the specified DEM accuracies and includes three different parts [11]: i) The calibration of the baseline between both satellites, ii) the adjustment of instrument internal delays to allow for a radargrammetric determination of the coarse absolute height, i.e., to estimate the absolute phase offset, and iii) the correction of phase offsets to tune the precise absolute height location of the DEM in the order of a few meters. This way, the DEM generation relies purely on the radar and GPS measurements recorded by the two satellites. ICESat [12] reference heights are only used in a final step to correct for residual offsets of a few meters. A systematic and data driven processing chain performs the precise synchronization, focusing and interferometric processing to scene-based Raw

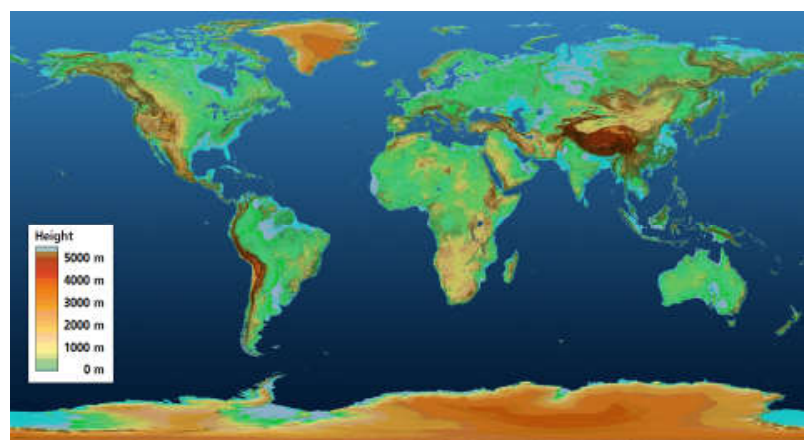

Fig. 2. The global TanDEM-X DEM, which has been available for scientific and commercial applications since September 2016. 
DEMs. After a final block adjustment and ICESat calibration, about 500,000 Raw DEMs were mosaicked together to the final global TanDEM-X DEM (see Fig. 2).

The quality of the acquired data has been constantly monitored throughout the years, allowing for the development of an optimized acquisition and processing strategy. The obtained results [13] confirm the outstanding capabilities of the system, with an overall absolute height accuracy of just $3.49 \mathrm{~m}$, which is well below the $10 \mathrm{~m}$ mission specification. Excluding highly vegetated and snow-/ice-covered regions, characterized by radar wave penetration phenomena and consequently strongly affected by volume decorrelation, it improves to $0.88 \mathrm{~m}$. Also, the relative height accuracy, which quantifies the random noise contribution within the final DEM, is well within specifications. Finally, the product is also virtually complete with $99.89 \%$ coverage.

The scientific exploitation of TanDEM-X is not limited to the DEM and the unique capabilities enable numerous secondary mission objectives based on along-track interferometry as well as new bistatic and multistatic SAR techniques. Indeed, some of these experiments were directly performed during the DEM acquisition phase, when suitable geometries were available. Moreover, regular acquisitions over selected super test sites enabled multi-temporal analyses. A dedicated science phase after the DEM acquisitions included: 1) up to $4 \mathrm{~km}$ cross-track baselines, 2) operation in the so-called Dual-Receive Antenna (DRA) mode, and 3) a period in pursuit monostatic flight formation.

Comparisons of the TanDEM-X DEM with the SRTM or among multi-temporal TanDEM-X data revealed dramatic changes and the height dynamic in the Earth's topography especially over ice and forests. It has been therefore decided to acquire data for a global change layer and the so-called change DEM will become available in 2021. Despite being well beyond their design lifetime, both satellites are still fully functional and have enough consumables for several additional years. Therefore, bistatic operations continue with a focus on changes in the cryosphere and biosphere.

\section{TANDEM-L}

Tandem- $\mathrm{L}$ is a proposal for an innovative L-band SAR mission for the systematic observation of dynamic processes on the Earth's surface with hitherto unparalleled quality and resolution [6], [7]. Due to the novel imaging techniques and the vast recording capacity of up to 8 Terabytes/day, it will provide vital information for addressing pressing scientific questions in the biosphere, geosphere, cryosphere and hydrosphere, and will make an essential contribution to better understand the Earth system and its dynamics.

The Tandem-L mission concept is based on the use of two SAR satellites operating in $\mathrm{L}$ band with variable formation flight configurations (see Fig. 3) and is distinguished by its high degree of innovation. Examples are polarimetric SAR interferometry (PolInSAR) for measuring forest height; multipass coherence tomography for determining the vertical structure of vegetation and ice; the utilization of the latest digital beamforming techniques in combination with a large deployable reflector for increasing the swath width and imaging capability.

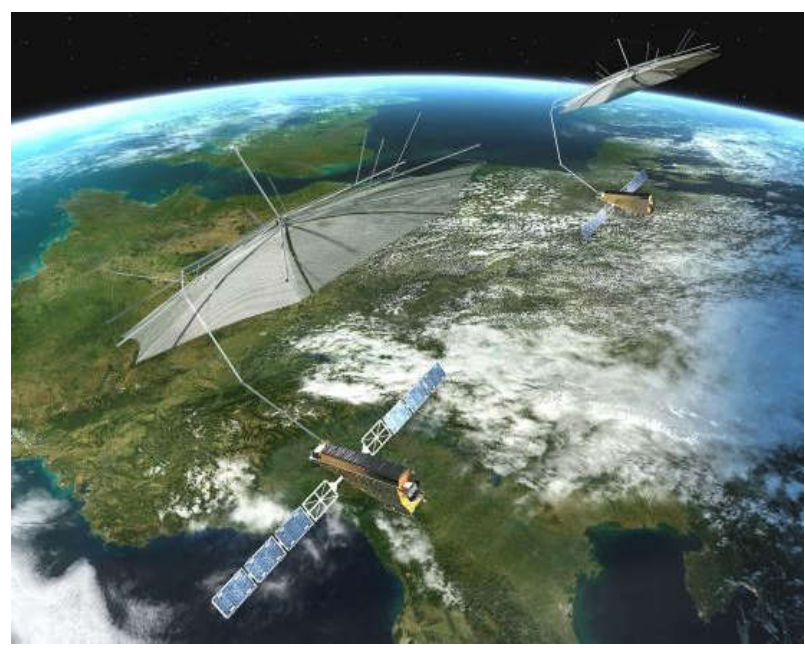

Fig. 3. Artist's impression of the Tandem-L satellite twins flying in close formation. The single-pass interferometric mode with adjustable across-track baselines is especially tomographic imaging of volume scatterers.

\section{A. Mission Objectives}

The Earth system is constantly changing, and dynamic processes occur in different spheres and at different time scales. Fig. 4 shows a number of selected examples to illustrate the spectrum of observation intervals needed to analyze important dynamic processes in the different Earth spheres. Tandem- $\mathrm{L}$ has been designed to observe a wide range of processes at adequate time intervals. Owing to its novel imaging techniques and its great acquisition capacity, Tandem-L will deliver urgently-required information for finding solutions to pressing scientific questions in the domain of the bio-, geo-, cryo- and hydrosphere. In this way, Tandem-L will significantly contribute to obtaining a better understanding of the Earth system and its dynamics.

Important mission goals are the global measurement of forest biomass and its variation in time for a better understanding of the carbon cycle; the systematic monitoring of deformations of the Earth's surface on a millimeter scale for the investigation of earthquakes and risk analysis; the quantification of glacier motion and melting processes in the polar regions; the fine scale measurement of variations in the near-surface soil moisture, as well as observations of the dynamics of ocean surfaces and ice drift. Tandem-L data will allow for the estimation of seven essential climate variables in a single satellite mission.

\section{B. Mission Concept}

The Tandem-L mission concept relies on a systematic data acquisition strategy using two cooperating L-band SAR satellites flying in close formation, building a single-pass across-track interferometer. A sun-synchronous orbit at an altitude of $745 \mathrm{~km}$ (at the equator) and a repeat cycle of 16 days has been selected. This orbit ensures full global coverage in the quad-polarized mode providing a swath width of 175 $\mathrm{km}$. Since the single- and dual-polarized modes provide a doubled swath width of $350 \mathrm{~km}$, each point on the Earth can be mapped with at least two incident angles from both ascending and descending passes. The satellite system will be operated in the following basic measurement modes: 


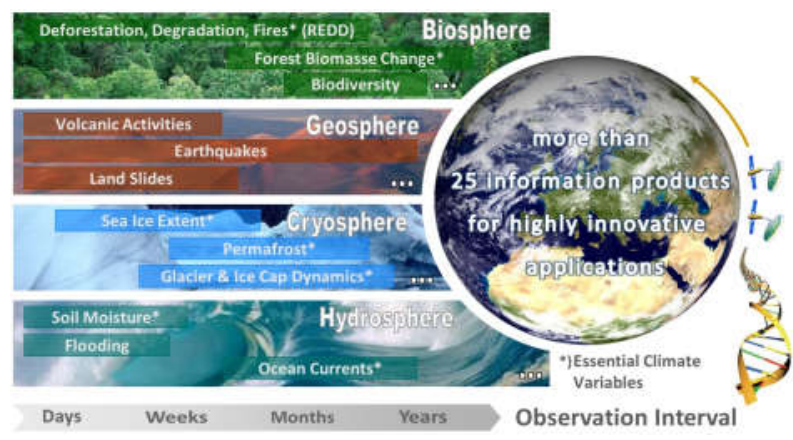

Fig. 4. Tandem-L provides a unique observatory to monitor dynamic processes in the bio-, geo-, cryo-, and hydrosphere. A highly innovative instrument technology enables short observation intervals, as are required for the systematic monitoring of the Earth system and its dynamics.

1) The 3-D structure mode uses both satellites to collect fully polarimetric and interferometric SAR data with adjustable across-track baselines and is especially designed for the three-dimensional surveying and tomographic imaging of volume scatterers, such as vegetation, ice, snow, and dry soil/sand. The basis of the 3-D structure mode is the combination of polarimetric SAR interferometry with multiple baseline SAR tomography. The repeated tomographic observations will provide a unique dataset for the scientific monitoring of internal structure dynamics in vegetation, soil and ice. A further important application is the simultaneous generation of both a digital surface and a digital terrain model, thereby complementing and updating the digital elevation data acquired by TanDEM-X.

2) The deformation mode employs repeat-pass interferometry to systematically monitor small and large-scale shifts on the Earth's surface with millimeter accuracies [6]. Operating in staggered SAR mode, a swath width of $350 \mathrm{~km}$ with a range and azimuth resolution of 5 and $7 \mathrm{~m}$, respectively, will support the generation of consistent image stacks for large contiguous areas with frequent updates. 3-D motion vectors are derived by combining data acquired from ascending and descending orbits at different incident angles, as well as in right- and left-looking configurations. Important applications are the large-scale monitoring of tectonic shifts at plate boundaries, the regular observation of volcanoes, the surveillance of urban subsidence, and systematic surveys of potential landslide areas.

\section{Staggered SAR}

The Tandem-L science requirements are met through an advanced instrument with capabilities beyond that of any known SAR sensor. Its key feature is the combination of a large deployable reflector antenna of $15 \mathrm{~m}$ diameter with a digital feed array [6], [7]. This makes possible a flexible beam shaping on transmit for optimum illumination of up to $350 \mathrm{~km}$ swath width. Digital beamforming on receive allows simultaneous imaging of multiple sub-swaths through multiple elevation beams, but 'blind ranges' (i.e., range bins without an echo signal due to pulse transmission at that particular time) are present between adjacent sub-swaths, as the radar cannot receive while it is transmitting. Staggered SAR is an innovative concept, which can overcome this issue by continuous variation of the pulse repetition interval (PRI), resulting in different positions of the blind ranges for each transmitted pulse [14]. A method has been developed to select the PRIs of the sequence such that two consecutive samples in the azimuth direction are never missed [15]. In addition, the signal is properly oversampled in azimuth, so that it is possible to accurately interpolate the data on a uniform grid and obtain a high-resolution SAR image over a wide continuous swath. The oversampling in azimuth determines the increase of the data volume to be downlinked, which can, however, be significantly reduced by filtering and decimating the data on board [16].

\section{Observation Concept \& Mission Products}

The Tandem-L mission will acquire global radar images in short repeat cycles (up to twice per week) in order to provide answers to the various scientific questions detailed above. A systematic global data observation scenario optimally meets the various scientific requirements while leveraging synergies, such as using a single radar image in several higher-level information products to the largest extent possible. To this end, the overall system is designed to allow the satellites to record up to 8 Terabytes of raw radar data per day and to download these data via a Ka-band datalink to a global network of ground stations.

The Tandem-L mission will generate a broad range of SAR and higher-level products. SAR products contain raw data or image data from monostatic or bistatic acquisitions. A unique feature and major challenge of the Tandem-L mission is the systematic generation of higher-level products, including forest height, structure and biomass, various surface deformation and displacement products, as well as digital elevation models. Additional products for applications in the hydro- and cryosphere are expected to be developed by the scientific community in the course of the mission.

\section{E. Approval Status}

The Tandem-L mission will set new standards in Earth observation, observe global change with a new quality and enable important recommendations for action. Currently, efforts are underway to secure funding within a research program for large-scale facilities in Germany. Additionally, efforts are being performed to realize this mission within the framework of the European Copernicus program.

\section{High-RESOLUTION WIDE-SWATH (HRWS) MISSION}

Within the radar roadmap of the German space program, a so-called High-Resolution Wide-Swath (HRWS) mission is planned for a launch in 2026/27. The HRWS mission aims at continuing and enhancing the very successful German X-band radar program. HRWS is intended to further provide the scientific community, the German national institutions and the international commercial sector with high-resolution SAR data acquired in new monostatic and multistatic imaging modes [17]. The HRWS system is also a chance to strengthen international collaborations and enables complementarity with other satellite data.

In preparation for a future X-band SAR mission, first technological developments were initiated by the DLR Space Agency in 2006. As a result of these developments, it was decided in 2016 to proceed with the HRWS mission and to conduct a feasibility study in the scope of a phase 0/A study. The starting point was a full-fledged digital beamforming system featuring SCan-On-REceive (SCORE, [21]) technique in combination with multiple azimuth phase centers (MAPS, [22]) to achieve a wide swath with a high azimuth resolution. 
In the phase 0 study it became clear that such a system did not adequately meet the users' needs and was not affordable within the budgetary constraints. Taking advantage of the new ITU frequency allocation in X-band allowing a bandwidth of up to $1200 \mathrm{MHz}$, a frequency scanning functionality (F-SCAN) was proposed instead of SCORE. The F-SCAN method can be implemented with much less hardware complexity than SCORE by using an analogue frequency scanning approach in elevation [19]. F-SCAN offers a number of unique features not achievable with the SCORE technique, such as high signal-to-noise performance with reduced peak power requirements, improved impulse response sidelobe suppression and an almost overhead free data sampling of the echo window. Unlike SCORE, F-SCAN uses the pencil beam in both transmit and receive. This not only leads to a higher system gain, but also has a better suppression of ambiguous targets.

A decrease of the echo window duration is achieved by matching the signal chirp ramp of the transmitted pulse to the travel time of the received echo window by the imaged swath. This enables high duty ratios to be achieved with a pulse duration even longer than the reception window. In combination with the use of the high gain pencil beam in TX and RX this results in a considerable improvement of the signal-to-noise ratio and at the same time eliminates non-valid data within the sampled receive window. As the antenna beam scans the swath both during transmit and receive, the energy is evenly distributed over the entire swath, resulting in an improved performance at far range. A further feature is the directly achieved spectral shaping, which leads to excellent sidelobe characteristics of the impulse response. Furthermore, the electronic beam steering in azimuth is complemented by mechanical steering, using Control Moment Gyroscopes, which provides a very high agility of the system in range and azimuth to increase access area and improve azimuth resolution.

At the end of phase 0 , the mission definition review concluded that interferometric capabilities should be added to enhance this concept in order to fulfill the majority of user needs.

\section{A. Mission Concept}

The current HRWS baseline concept consists of a powerful main satellite acting as an illuminator as well as three much smaller receive-only relay satellites to be used in formation flight. It uses the MirrorSAR concept developed by the DLR Microwaves and Radar Institute, a new multi-static approach for robust single-pass interferometry and generation of digital elevation models [18]. Compared to previously published bi- and multistatic SAR systems, the receiver satellites are considerably simplified, as their main functionality is reduced to a microwave mirror (or space transponder) which routes the radar echoes towards the transmitter. The forwarded radar signals are then coherently demodulated within the transmitter satellite by using the same oscillator that had been used for radar pulse generation. The main benefits of the MirrorSAR concept [18] are: i) effective low-cost implementation of a multistatic SAR system with multiple baselines for high-resolution SAR interferometry; ii) considerable simplification of the hardware and thermal design of the receiver satellites, which lowers their mass, size and power demand; iii) opportunity for bistatic SAR synchronization without a dedicated synchronization link, and iv) opportunity for efficient multi-satellite data compression

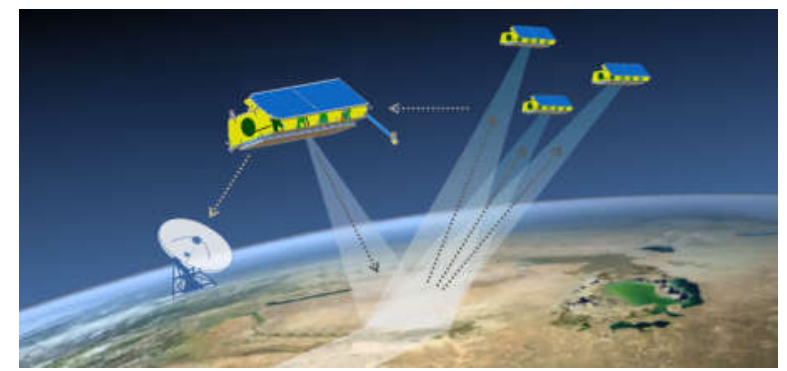

Fig. 5. MirrorSAR concept [18] as the current baseline for the HRWS mission.

which lowers the downlink requirements and reduces the mission operation costs. Due to the multichannel capability of the main HRWS satellite for digital beamforming, no additional receiver chain is required for digitization of the MirrorSAR signals. This means that the MirrorSAR concept can be implemented with a small increase of the complexity of the main HRWS satellite hardware.

\section{B. Application Fields of the HRWS Mission}

During the HRWS phase 0 study an extensive user need assessment has been carried out to gather the needs and requirements of the main user groups. The user groups can be characterized by their needs regarding data products and services, information handling and data ordering. The principal mission end-user groups are science users, German (civilian and military) institutional users as well as international commercial users. Based on the user need assessment the main fields of applications for HRWS are surface motion monitoring, change detection, thematic mapping, maritime surveillance, image and geo-intelligence as well as the generation of digital elevation models. Based on the technical requirements (e.g., resolution, swath width, repetition rate) for those main fields of applications, product specifications of HRWS were developed for the spotlight, stripmap and ScanSAR imaging modes.

The acquisition modes of HRWS will significantly expand the monitoring capabilities of the TerraSAR-X and TanDEM-X missions. In spotlight mode HRWS will provide a maximum spatial resolution of $25 \mathrm{~cm}$ with $25 \mathrm{x} 25 \mathrm{~km}^{2}$ image size in sliding spotlight mode and single polarization and $15 \times 15 \mathrm{~km}^{2}$ in quad-polarization mode. A new "Spotlight Theatre" imaging mode will be able to acquire data of up to 8 areas with $7.5 \times 7.5 \mathrm{~km}^{2}$ coverage and $25 \mathrm{~cm}$ resolution within an area of interest of $100 \mathrm{~km}^{2}$. The azimuth resolution of the stripmap mode will be $1 \mathrm{~m}$ and $3 \mathrm{~m}$ covering a swath width of $50 \mathrm{~km}$ and $80 \mathrm{~km}$, respectively. Quad-pol acquisitions in stripmap mode will be available in 2-m spatial resolution with $30 \mathrm{~km}$ swath width. The ScanSAR mode will be able to provide imagery in various resolutions and polarization modes with a maximum swath of $500 \mathrm{~km}$ in single pol (NESZ $<-23$ $\mathrm{dB})$ and with a range and azimuth resolution of $2 \mathrm{~m} \times 16 \mathrm{~m}$, respectively. The multistatic capabilities of HRWS will provide data with an 11-day interferometric repeat cycle. The multistatic mission goal will be a global digital elevation model at 4-m posting with a relative height accuracy of $2 \mathrm{~m}$. The flexibility of HRWS's multistatic mission design will allow the generation of on-demand local to regional digital elevation model products.

Based on the user demand several geo-information products and services have been identified as candidates for 
implementation in the HRWS service segment: i) surface movement mapping, ii) ground control point generation, iii) change detection product generation, iv) maritime surveillance and v) radargrammetric digital elevation model generation. Due to the multistatic capabilities of HRWS new geoinformation products and services have been identified as candidates for implementation in the HRWS service segment, as for example 3D/4D change detection, sea ice topography, SAR tomography over urban areas and ground moving target indication (GMTI). To fulfil the user demand for DEM and new multistatic information products, the HRWS mission will provide a global as well as local to regional on-demand Digital Elevation Models (DEM) at 4-m posting with a relative height accuracy of $2 \mathrm{~m}$.

With HRWS, nearly 40 years of successful X-band SAR development in Germany will continue. Thus, the mission will provide data continuity for scientific, institutional and commercial users. Presently, the DLR Space Agency is planning to start with Phase B in 2021, leading to a satellite launch in the 2026/27 timeframe.

\section{CONCLUSIONS AND OUTLOOK}

Spaceborne SAR sensors have the only technology that can provide all-weather day-and-night high-resolution information about Earth's dynamic processes on a global scale. Many applications became mature and are an integral part in operational services of geo-information products as well as in environmental, geoscience and climate research [20]. We have now entered into a golden age for spaceborne SAR, including both full-fledged SAR systems (e.g., TerraSAR-X and TanDEM-X - DLR, Germany; COSMOSkyMed - ASI, Italy; Radarsat Constellation Mission - CSA, Canada; ALOS-2 - JAXA, Japan; NISAR - NASA/ISRO, USA/India; RISAT - ISRO, India, Sentinel-1A/B/C/D and ROSE-L - ESA/EC and BIOMASS - ESA) as well as a number of private initiatives based on NewSpace approaches (e.g. ICEYE, Capella, Synspective, PredaSAR, Umbra) aiming to establish a constellation of low-cost SAR systems with the goal to provide a revisit time as low as one hour. Future SAR mission concepts with digital beamforming technology like Tandem-L, HRWS, NISAR, ROSE-L, ALOS-4 and Sentinel-1NG are being developed which will outperform the imaging capacity of current SAR systems by approximately one order of magnitude. Germany has been playing a key role in this new development with its own national space radar program as well as with its contributions to the European SAR missions. Today, Germany is a largest contributor to the European Earth observation program, including the scientific program (i.e., ESA Earth Explorer program consisting of BIOMASS and the candidate mission Harmony) as well as the ESA/EC Copernicus program with the operational missions (Sentinel-1A/B, Sentinel-1C/D and follow-on Sentinel-1NG as well as ROSE-L).

\section{REFERENCES}

[1] A. Freeman, M. Zink, E, Caro, A. Moreira, L. Veilleux, M. Werner, "The legacy of the SIR-C/X-SAR radar system: 25 years on," Remote Sens. Environ., vol. 231, 2019.

[2] T. G. Farr, P. Rosen, E. Caro, R. Crippen, R. Duren,S. Hensley, M. Kobrick, M. Paller, E. Rodriguez, L. Roth, D. Seal, S. Shaffer, J. Shimada, J. Umland, M. Werner, M. Oskin, D. Burbank, D. Alsdorf, "The Shuttle Radar Topography Mission," Review Geophys., vol. 45, 2007.
[3] M. Werner, "Shuttle Radar Topography Mission (SRTM) Mission Overview," Frequenz: Journal of Telecommun., vol. 55, pp. 75-79, 2001.

[4] A. Moreira, G. Krieger, I. Hajnsek, M. Werner, D. Hounam, S. Riegger, E. Settelmeyer, "TanDEM-X: A TerraSAR-X Add-On Satellite for Single-Pass SAR Interferometry,” Proc. IEEE Int. Geosci. Rem. Sens. Symp. (IGARSS), Anchorage, USA, 2004.

[5] G. Krieger, A. Moreira, H. Fiedler, I. Hajnsek, M. Werner, M. Younis, M. Zink, "TanDEM-X: A Satellite Formation for High Resolution SAR Interferometry," IEEE Trans. Geosci. Rem. Sens., vol. 45, no. 11, pp. 3317-3341, 2007.

[6] A. Moreira, G. Krieger, I. Hajnsek, K. Papathanassiou, M. Younis, F. López-Dekker, S. Huber, M. Villano, M. Pardini, M. Eineder, F. De Zan, A. Parizzi, "Tandem L: A Highly Innovative Bistatic SAR Mission for Global Observation of Dynamic Processes on the Earth's Surface," IEEE Geosci. Remote Sens. Mag., vol. 3, no. 2, pp. 8-23, 2015.

[7] G. Krieger, et.al., "Tandem L: Main Results of the Phase A Feasibility Study,” Proc. IEEE Int. Geosci. Rem. Sens. Symp. (IGARSS), Beijing, China, July 2016.

[8] R. Werninghaus and S. Buckreuss, "The TerraSAR-X Mission and System Design,” IEEE Trans. Geosci. Rem. Sens., vol. 48, no. 2, pp. 606-614, 2010.

[9] T. Kraus, B. Bräutigam, J. Mittermayer, S. Wollstadt, C. Grigorov, "TerraSAR-X Staring Spotlight Mode Optimization and Global Performance Predictions," IEEE J. Sel. Topics Appl. Earth Observ. Remote Sens., vol. 9, no. 3, pp. 1015-1027, 2016.

[10] P. Prats-Iraola, R. Scheiber, M. Rodriguez-Cassola, J. Mittermayer, S. Wollstadt, F. De Zan, B. Bräutigam, M. Schwerdt, A. Reigber, A. Moreira, "On the Processing of Very High-Resolution Spaceborne SAR Data", IEEE Trans. Geosci. Rem. Sens., vol. 52, no. 10, pp. 60036016, 2014.

[11] J. Hueso González, J. Walter Antony, M. Bachmann, G. Krieger, M. Zink, D. Schrank, M. Schwerdt, "Bistatic System and Baseline Calibration in TanDEM-X to Ensure the Global Digital Elevation Model Quality," ISPRS J. Photogramm. Remote Sens. , vol. 73, pp. 3-11, 2012.

[12] B. Schutz, H. Zwally, C. Shuman, D. Hancock, J. Di Marzio, "Overview of the ICESat Mission," Geophys. Research Lett., vol. 32, No. 21, 2005.

[13] P. Rizzoli, M. Martone, C. Gonzalez, C. Wecklich, D. Borla Tridon, B. Bräutigam, M. Bachmann, D. Schulze, T. Fritz, M. Huber, B. Wessel, G. Krieger, M. Zink, A. Moreira, "Generation and Performance Assessment of the Global TanDEM-X Digital Elevation Model," ISPRS J. Photogramm. Remote Sens., vol. 73, pp. 119-139, 2017.

[14] M. Villano, G. Krieger, G., A. Moreira, "A Novel Processing Strategy for Staggered SAR," IEEE Geosci. Remote Sens. Lett., vol. 11, no. 11, pp. 1891-1895, 2014.

[15] M. Villano, G. Krieger, A. Moreira, "Staggered SAR: High-Resolution Wide-Swath Imaging by Continuous PRI Variation," IEEE Trans. Geosci. Rem. Sens., vol. 52, no. 7, pp. 4462-4479, 2014.

[16] M. Villano, G. Krieger, A. Moreira, "Onboard Processing for Data Volume Reduction in High-Resolution Wide-Swath SAR," IEEE Geosci. Rem. Sens. Lett., vol. 13, no. 8, pp. 1173-1177, 2016.

[17] A. E. Nuncio Quiroz, M. Bartusch: "Next Generation of the German X-Band SAR: The Multi-static High Resolution Wide Swath Mission," ESA Living Planet Symp., Milan, Italy, May 2019.

[18] G. Krieger, M. Zonno, J. Mittermayer, A. Moreira, S. Huber and M. Rodriguez-Cassola, "MirrorSAR: A Fractionated Space Transponder Concept for the Implementation of Low-Cost Multistatic SAR Missions," Proc. Eur. Conf. Synth. Aperture Radar (EUSAR), 2018.

[19] C. Roemer, "Introduction to a New Wide Area SAR Mode Using the F-SCAN Principle", Proc. IEEE Int. Geosci. Remote Sens. Symp. (IGARSS), pp. 3844-3847, 2017.

[20] A. Moreira, P. Prats-Iraola, M. Younis, G. Krieger, I. Hajnsek, K. Papathanassiou, "A Tutorial on Synthetic Aperture Radar", IEEE Geosci. Remote Sens. Magazine, vol. 1, no. 1, pp. 6-43, March 2013.

[21] M. Suess, B. Grafmueller, R. Zahn, "A Novel High Resolution, Wide Swath SAR System", Proc. IEEE Int. Geosci. Remote Sens. Symp. (IGARSS), Sidney, Australia, 2001.

[22] N. Gebert, G. Krieger, A. Moreira, "Digital Beamforming on Receive: Techniques and Optimization Strategies for High-Resolution WideSwath SAR Imaging,” IEEE Trans. Aerosp. Electron. Syst., vol. 45, no. 2, pp. 564-592, 2009. 